\title{
Molecular dynamics and quantum chemical approaches in the study of the hydration of protonated cyclohexyldiamines
}

\author{
A.J. Lopes Jesus, J.A.S. Almeida, A.A.C.C. Pais \& J.S. Redinha
}

To cite this article: A.J. Lopes Jesus, J.A.S. Almeida, A.A.C.C. Pais \& J.S. Redinha (2014) Molecular dynamics and quantum chemical approaches in the study of the hydration of protonated cyclohexyldiamines, Molecular Physics, 112:2, 173-181, DOI: 10.1080/00268976.2013.805848

To link to this article: https://doi.org/10.1080/00268976.2013.805848

曲制 Published online: 14 Jun 2013.

Submit your article to this journal $\pi$

Џلll Article views: 104

View Crossmark data $\complement$

Citing articles: 1 View citing articles ๘ 


\title{
RESEARCH ARTICLE
}

\section{Molecular dynamics and quantum chemical approaches in the study of the hydration of protonated cyclohexyldiamines}

\author{
A.J. Lopes Jesus ${ }^{a, b, *}$, J.A.S. Almeida ${ }^{b}$, A.A.C.C. Pais ${ }^{b}$ and J.S. Redinha ${ }^{b}$ \\ ${ }^{a}$ Faculty of Pharmacy, University of Coimbra, Coimbra, Portugal; ${ }^{b}$ Department of Chemistry, University of Coimbra, Coimbra, Portugal
}

(Received 28 March 2013; final version received 11 May 2013)

\begin{abstract}
Explicit hydration of the neutral and charged cyclohexylamine and of the cyclohexyldiamine isomers in their mono- or diprotonated forms is investigated through classical molecular dynamics (MD) simulations in aqueous solutions combined with DFT calculations in amine-water complexes. The MD studies performed in the monoamines reveal that the structure of the hydration shell around the neutral amino group $\left(\mathrm{NH}_{2}\right)$ is quite distinct from that around the charged one $\left(\mathrm{NH}_{3}{ }^{+}\right)$. On average, the number of water molecules surrounding the two groups is calculated to be $\sim 2$ and $3-4$, respectively. The variation of the hydration structure prompted by the groups' proximity is discussed based on the data found for the mono- and diprotonated diamines. To have a more detailed picture of the water molecules' arrangement around the amino groups and of the amine-water hydrogen bonds, geometry optimisations in hydrates with up to six water molecules are carried out at the B3LYP/aug-cc-pVDZ level. Complexation energies are also computed. The main findings emerging from these calculations are found to be very helpful to rationalise the mutual influence of the amino groups and therefore to better elucidate the MD findings. The complementary nature of the two research methods is emphasised as an excellent tool in order to closely examine the hydration of polyamines, as exemplified for the cyclohexyldiamines.
\end{abstract}

Keywords: protonated cyclohexyldiamines; molecular dynamics; hydration shell; DFT calculations; amine-water complexes

\section{Introduction}

Primary amines are chemical compounds widely used in scientific laboratories and in industries as reagents and raw materials. The $\mathrm{NH}_{2}$ group is part of a large diversity of biomolecules, such as proteins, catecholamines and nucleic acids, playing a fundamental role in their biological function [1-3]. Because of its intrinsic acid-base character, the amino group can exist in the unprotonated (neutral) or protonated (cationic) form, depending on the solution $\mathrm{pH}$ [4-6].

Polyamines are involved in many important physiological functions, the interpretation of which has been the focus of a recent and promising research field [7-11]. Since the action of these compounds occurs frequently in aqueous media, their interaction with water assumes a particular significance and deserves special attention. The present paper intends to be a contribution to this objective. The molecules selected for this research are the cyclohexyldiamines (CHDAs) in the mono- and diprotonated forms, which prevail in aqueous solution at physiological $\mathrm{pH}$ $[4,5]$. Because of their simple conformational behaviour, mostly due to their rigid molecular backbone, this group of molecules is a suitable system to reveal the effect that the proximity of the amino groups has upon their interaction with water.
Some data concerning the explicit hydration of ammonium [12,13] and charged monoamines are available in the literature [14-18]. However, the number of publications dedicated to the hydration of charged diamines is relatively scarce $[4,19-21]$. The most relevant data were obtained through experimental studies on sequential gasphase hydration [19,21], as well as from computational calculations using the conductor-like continuum solvation model (CPCM) [4]. In these studies, the diamine hydration is fundamentally interpreted on energetic and conformational grounds. A step forward to better understand the behaviour of these molecules in aqueous solution can be achieved by evaluating the structural modifications on the first hydration shell around the neutral and charged amino groups induced by their proximity. To attain this goal, we will use computational approaches of studying hydration in which the solvent is explicitly represented.

Molecular dynamics (MD) simulations of infinitely dilute aqueous solutions of protonated amines and density functional theory (DFT) calculations on water-amine complexes are the two methods used in this study. MD is a powerful tool to describe the hydration shell of the solute molecule, but gives a rather convolved geometric and energetic description of the specific solute-solvent interactions. Conversely, quantum chemical calculations on complexes

*Corresponding author. Email: ajorge@qui.uc.pt 
provide accurate data on the energy and geometry of the molecular interactions, but not the complete picture regarding hydration. Therefore, a combination of both methods allows for a more focused inspection, characterisation and rationalisation of the structure of the CHDAs in aqueous solution to be established.

\section{Computational methods}

\subsection{Molecules}

For this investigation, we have selected some of the CHDA isomers in their mono- and diprotonated forms $\left(\mathrm{CHDA}^{+}\right.$ and $\mathrm{CHDA}^{2+}$ ), with both groups assuming an equatorial configuration. We focused mainly on the two extreme cases in terms of the amino groups' proximity, trans-1,2-cyclohexyldiamine $\left(\mathrm{t} 12^{+} / \mathrm{t} 12^{2+}\right)$ and trans-1,4cyclohexyldiamine $\left(\mathrm{t} 14^{+} / 14^{2+}\right)$, although the intermediate isomer, cis-1,3-cyclohexyldiamine $\left(\mathrm{c} 13^{+} / \mathrm{c} 13^{2+}\right)$, has been also included in the DFT calculations. To be used as a reference, neutral and protonated cyclohexylamines $\left(\mathrm{CHA}\right.$ and $\left.\mathrm{CHA}^{+}\right)$were also studied. For all molecules, the most stable structures in aqueous solution predicted at the CPCM/MP2/aug-cc-PVDZ level [22] were taken as the starting geometries for the MD simulations and DFT calculations.

\subsection{MD simulations}

Topologies for the molecular residues, compatible with the GROMOS 96 43a1 force field [23], were generated by the PRODRG server [24] and the atomic charges were calculated at the CPCM/MP2/aug-cc-pVDZ level by fitting the electrostatic potential in accordance with the charges from electrostatic potentials grid scheme proposed by Breneman and Wiberg [25]. The solute molecules were kept at the centre of a cubic box ( $2.5 \mathrm{~nm}$ length) filled with ca. 500 simple point charge water molecules. Topology for the simple point charge water was used as made available in the original force field. Charge neutrality in the box was kept by adding one or two chloride ions.

All simulations were carried out in the $N p T$ ensemble and under periodic boundary conditions, using the GROMACS package, version 4.5.4 [26]. A standard time step of $2 \mathrm{fs}$ was used for both the equilibration and the production runs. Non-bonded interactions were computed on the basis of a neighbour list that was updated every 10 steps. Longrange electrostatics was computed by using the particle mesh Ewald (PME) method. For Lennard-Jones energies, a cut-off of $1.4 \mathrm{~nm}$ was applied. Temperature $(298 \mathrm{~K})$ and pressure $(1 \mathrm{bar})$ were coupled to the Berendsen external baths, with coupling constants of 0.1 and $0.5 \mathrm{ps}$, respectively. Each system was firstly subjected to an energy minimisation step and then left to evolve up to $40 \mathrm{~ns}$. The last $20 \mathrm{~ns}$ of production runs were subsequently subjected to the standard analysis, such as distances and radial distribution functions [RDF, $g(r)]$. Autocorrelation function (ACF) of the hydrogen bonds established between the amine and water molecules were computed using the standard analysis available with GROMACS. A cut-off distance (hydrogenacceptor) of $0.27 \mathrm{~nm}$ and a cut-off angle (hydrogen-donoracceptor) of $30^{\circ}$ have been imposed. Residence times were then calculated by dividing the integral over time of the ACF duly normalised by the average number of H-bonds, as described elsewhere [27].

\subsection{DFT calculations in amine-water complexes}

Unless otherwise stated, amine-water complexes (hydrates) of the molecules under consideration were built by placing three water molecules around each charged or neutral amino group. This number of water molecules is that corresponding to the number of sites in the amino groups able to act as donors or acceptors in the H-bonds with water. The hydrates were then fully optimised in the framework of the Kohn-Sham DFT using the B3LYP functional [28-30] and the augmented correlation-consistent polarised valence double-zeta (aug-cc-pVDZ) basis set [31,32]. Basis set superposition error (BSSE) was taken into account by using the Boys and Bernardi counterpoise correction method [33,34]. This correction has been included in each step of the gradient optimisation and each water molecule was taken as an individual fragment. Geometry optimisation was followed by a vibrational frequency calculation at the same level of theory in order to check if the optimised hydrates corresponded to true minima (this was confirmed by the absence of imaginary vibrational frequencies) and to estimate the values of the thermodynamic quantities (enthalpy, Gibbs energy and entropy) at $298.15 \mathrm{~K}$. All calculations were performed using the Gaussian 03 program package [35].

The formation of the amine-water complex in gas phase can be represented by

$$
\mathrm{Am}(g)+x \mathrm{H}_{2} \mathrm{O}(g) \rightarrow \text { Am. } x \mathrm{H}_{2} \mathrm{O}(g),
$$

where Am (abbreviation of amine) stands for the monoamines or diamines in the neutral or protonated forms and $x$ for the number of water molecules added to the molecules $\left(x=3\right.$ for $\mathrm{CHA}$ or $\mathrm{CHA}^{+}$and $x=6$ for the mono- or diprotonated CHDAs).

The energy of complex formation ( $\left.\Delta E_{\text {complex }}\right)$ was calculated as

$$
E_{\text {complex }}=E\left(\text { Am. } x \mathrm{H}_{2} \mathrm{O}\right)-\left[\left(E(\mathrm{Am})+x E\left(\mathrm{H}_{2} \mathrm{O}\right)\right],\right.
$$

where $E\left(\mathrm{Am} . x \mathrm{H}_{2} \mathrm{O}\right)$ is the $\mathrm{BSSE}$-corrected electronic energy of the optimised hydrate, $E(\mathrm{Am})$ the electronic energy of the optimised isolated amine and $E\left(\mathrm{H}_{2} \mathrm{O}\right)$ the electronic energy of an optimised isolated water molecule. An identical expression to Equation (2) has been used to calculate 
Table 1. Distance $\left(r_{M} / \mathrm{nm}\right)$ and height $\left(g_{M}\right)$ of the peaks and hydration numbers $\left(N_{w}\right)$ obtained from the different RDFs. ${ }^{a}$

\begin{tabular}{|c|c|c|c|c|c|c|}
\hline Molecule & $\mathrm{N}\left(\mathrm{NH}_{2}\right)-\mathrm{O}_{w}$ & & & $\mathrm{~N}\left(\mathrm{NH}_{3}{ }^{+}\right)-\mathrm{O}_{w}$ & & \\
\hline & $r_{M} / \mathrm{nm}$ & $g_{M}$ & $N_{w}$ & $r_{M} / \mathrm{nm}$ & $g_{M}$ & $N_{w}$ \\
\hline CHA & 0.28 & 1.14 & 2.18 & & & \\
\hline $\mathrm{CHA}^{+}$ & & & & 0.29 & 2.11 & 3.54 \\
\hline $\mathrm{t} 14^{+}$ & 0.28 & 1.14 & 2.57 & 0.29 & 2.58 & 3.87 \\
\hline $\mathrm{t} 12^{+}$ & - & - & - & 0.29 & 1.97 & 3.23 \\
\hline $\mathrm{t} 14^{2+}$ & & & & 0.29 & 2.67 & 4.09 \\
\hline \multirow[t]{3}{*}{$\mathrm{t} 12^{2+}$} & & & & 0.29 & 2.83 & 4.46 \\
\hline & $\mathrm{H}\left(\mathrm{NH}_{2}\right)-\mathrm{O}_{w}$ & & & $\mathrm{H}\left(\mathrm{NH}_{3}{ }^{+}\right)-\mathrm{O}_{w}$ & & \\
\hline & $r_{M} / \mathrm{nm}$ & $g_{M}$ & $N_{w}$ & $r_{M} / \mathrm{nm}$ & $g_{M}$ & $N_{w}$ \\
\hline CHA & $0.22 ; 0.32$ & $0.37 ; 0.93$ & 0.40 & & & \\
\hline $\mathrm{CHA}^{+}$ & & & & $0.20 ; 0.32$ & $1.43 ; 1.04$ & 1.01 \\
\hline $\mathrm{t} 14^{+}$ & $0.21 ; 0.32$ & $0.44 ; 0.94$ & 0.34 & $0.19 ; 0.33$ & $1.70 ; 1.11$ & 1.03 \\
\hline \multirow[t]{3}{*}{$\mathrm{t} 12^{+}$} & $0.22 ; 0.37$ & $0.47 ; 0.89$ & 0.36 & $0.20 ; 0.33$ & $1.14 ; 1.00$ & 1.00 \\
\hline & & & & $0.20 ; 0.33$ & $0.89 ; 1.05$ & 0.93 \\
\hline & & & & $0.20 ; 0.33$ & $1.32 ; 0.95$ & 1.03 \\
\hline $\mathrm{t} 14^{2+}$ & & & & $0.19 ; 0.33$ & $1.73 ; 1.14$ & 1.06 \\
\hline \multirow{3}{*}{$\mathrm{t} 12^{2+}$} & & & & $0.19 ; 0.33$ & $1.82 ; 1.12$ & 1.15 \\
\hline & & & & $0.19 ; 0.33$ & $1.59 ; 1.22$ & 1.13 \\
\hline & & & & $0.19 ; 0.33$ & $1.77 ; 1.16$ & 1.13 \\
\hline
\end{tabular}

${ }^{a}$ Values of $N_{w}$ were obtained by integration of the RDF up to the first minimum. The values separated by semicolon refer to the first and second peaks of the $\mathrm{H}\left(\mathrm{NH}_{2}\right)-\mathrm{O}_{w}$ and $\mathrm{H}\left(\mathrm{NH}_{3}{ }^{+}\right)-\mathrm{O}_{w} \mathrm{RDFs}$.

the enthalpy $\left(\Delta H_{\text {complex }}\right)$ and Gibbs energy $\left(\Delta G_{\text {complex }}\right)$ of complexation.

\section{Results and discussion}

\subsection{Molecular dynamics}

Relevant data on the structure of the hydration shells around the amino groups can be drawn from the RDFs of the oxygen or hydrogen atoms of the water molecules around the aminic nitrogen or hydrogen atoms. They are characterised here by the positions of the maxima $\left(r_{M}\right)$ and minima $\left(r_{m}\right)$ and by the values of the $g(r)$ function at these points, designated as $g_{M}$ and $g_{m}$, respectively. The values of the integral of $g(r)$ up to the first minima have also been calculated since they represent the hydration number $\left(N_{w}\right)$. All RDF-related properties are summarised in Table 1.

Let us begin the discussion by considering the nitrogenwater oxygen $\left(\mathrm{O}_{w}\right) \mathrm{RDFs}$ for the neutral $\left[\mathrm{N}\left(\mathrm{NH}_{2}\right)-\mathrm{O}_{w}\right]$ and protonated $\left[\mathrm{N}\left(\mathrm{NH}_{3}{ }^{+}\right)-\mathrm{O}_{w}\right]$ amino groups, which are displayed in Figure 1. The $\mathrm{N}\left(\mathrm{NH}_{2}\right)-\mathrm{O}_{w} \mathrm{RDF}$ obtained for CHA exhibits a first peak at $r_{M}=0.28 \mathrm{~nm}\left(g_{M}=1.1\right)$, followed by a minimum at $r_{m}=0.32 \mathrm{~nm}\left(g_{m}=0.62\right)$ and by a second very broad region before attaining the asymptotic value $g(r)=1$. The value of $r_{M}$ corresponds to the more probable distance between the nitrogen atom and the oxygen atoms of the water molecules in the first hydration shell. As $r_{M}$ is smaller than the sum of the van der Waals radii of the $\mathrm{N}$ and $\mathrm{O}$ atoms $(0.307 \mathrm{~nm})$ [36], one can conclude that the interactions between the amino group and the water molecules are of the hydrogen bonding (H-bond) type. Note that at this stage we are not able to distinguish $\mathrm{N}-\mathrm{H} \cdots \mathrm{O}$ from $\mathrm{N} \cdots \mathrm{H}-$
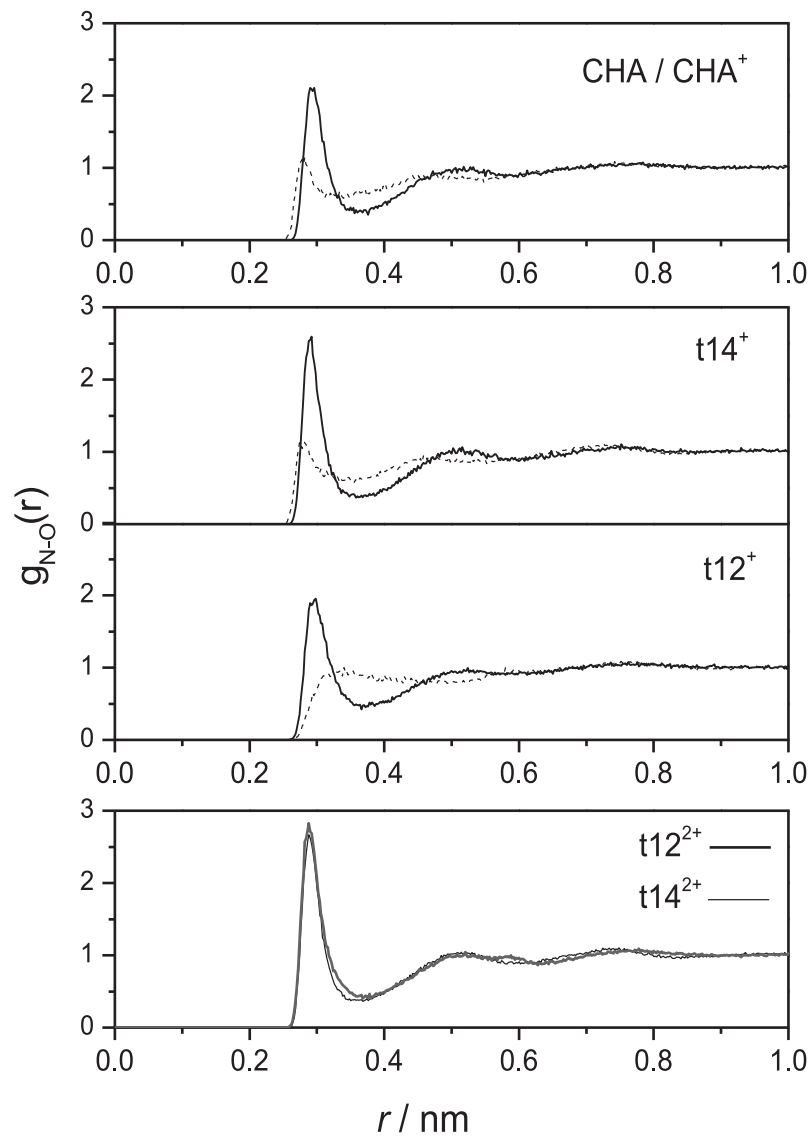

Figure 1. $\mathrm{N}\left(\mathrm{NH}_{2}\right)-\mathrm{O}_{w}$ (dashed lines) and $\mathrm{N}\left(\mathrm{NH}_{3}{ }^{+}\right)-\mathrm{O}_{w}$ (solid lines) RDFs for the different molecules under study. For $\mathrm{t} 12^{+}$and $\mathrm{t} 12^{2+}$ the three hydrogen atoms have been discriminated. 
$\mathrm{O}_{w}$ bonds because both have identical $\mathrm{N} \cdots \mathrm{O}_{w}$ distances. Integration of $g(r)$ up to the first minimum yields $N_{w}=2.2$, meaning that on average the $\mathrm{NH}_{2}$ group is coordinated by two water molecules. The curve profile for $r>r_{m}$ indicates that the influence of this group on the water structure beyond the first hydration shell is negligible. Similar values of $r_{M}, r_{m}$ and $N_{w}$ are given by the $\mathrm{N}\left(\mathrm{NH}_{2}\right)-\mathrm{O}_{w} \mathrm{RDFs}$ obtained from MD simulations of methylamine in aqueous solution [15,37].

From Figure 1, one can see that the profile of the $\mathrm{N}\left(\mathrm{NH}_{2}\right)-\mathrm{O}_{w}$ RDF is not much affected by the presence of an $\mathrm{NH}_{3}{ }^{+}$group in the most remote position $\left(\mathrm{t}^{+} 4^{+}\right)$but is strongly affected when this group is vicinal relative to $\mathrm{NH}_{2}$. Indeed, the distribution function obtained for $\mathrm{t} 12^{+}$ reveals a depletion of water molecules around the group, comparatively to the monoamine. This behaviour is likely to be related with the formation of an $\mathrm{N}^{+}-\mathrm{H} \cdots \mathrm{N}$ intramolecular H-bond, which decreases the ability of the $\mathrm{NH}_{2}$ group to interact with water. To confirm this, we have examined the $\mathrm{H}\left(\mathrm{NH}_{3}{ }^{+}\right) \cdots \mathrm{N}\left(\mathrm{NH}_{2}\right)$ distance along the trajectory and found that for $40 \%$ of the trajectory time this distance is less than or equal to $0.26 \mathrm{~nm}$, a value that is within the criteria commonly accepted for the formation of an H-bond [38,39].

The $\mathrm{N}\left(\mathrm{NH}_{3}{ }^{+}\right)-\mathrm{O}_{w}$ RDF profiles differ significantly from those obtained for the neutral group. The first peak at $r_{M}=0.29 \mathrm{~nm}$ is more intense $\left(g_{M}=1.94-2.83\right)$ and sharper and the first minimum at $r_{m} \approx 0.39 \mathrm{~nm}$ is deeper $\left(g_{m}=0.38-0.45 \mathrm{~nm}\right)$. This means that by comparison to the neutral amino group, the hydration shell around $\mathrm{NH}_{3}{ }^{+}$ is much more structured. According to the values of $N_{w}$, it involves 3.5-4.5 water molecules, in agreement with the hydration numbers found for ammonium and methylammonium $[13,15]$. The second broad peak observed between 0.39 and $0.60 \mathrm{~nm}$ is probably related to the formation of a second hydration shell.

Although all $\mathrm{N}\left(\mathrm{NH}_{3}{ }^{+}\right)-\mathrm{O}_{w}$ RDFs exhibit identical patterns, there are some differences among them that should be highlighted. As far as the monoprotonated forms are concerned, the comparison of the curves obtained for $\mathrm{t} 14^{+}$ and $\mathrm{CHA}^{+}$shows that the values of $g_{M}$ and $N_{w}$ are higher for the first (Table 1), that is, the presence of the neutral group seems to favour the interaction of $\mathrm{NH}_{3}{ }^{+}$with water. We have to look for this unexpected behaviour in an eventual mutual interference of the hydration shells of both groups. The results of the DFT calculations on the hydrates that will be presented later in this paper will help to clarify this behaviour. In $\mathrm{t}^{+}{ }^{+}$, the decrease of the first maximum intensity and of $N_{w}$ relative to the $114^{+}$results from the formation of the intramolecular $\mathrm{H}$-bond. When both groups are charged, what happens in $\mathrm{t} 12^{2+}$ and $\mathrm{t} 14^{2+}$, the first peak maximum is higher than that in $\mathrm{CHA}^{+}$and the hydration number increases (see Table 1). The same effect is observed within the diamine isomers as the charged groups approximate each other.

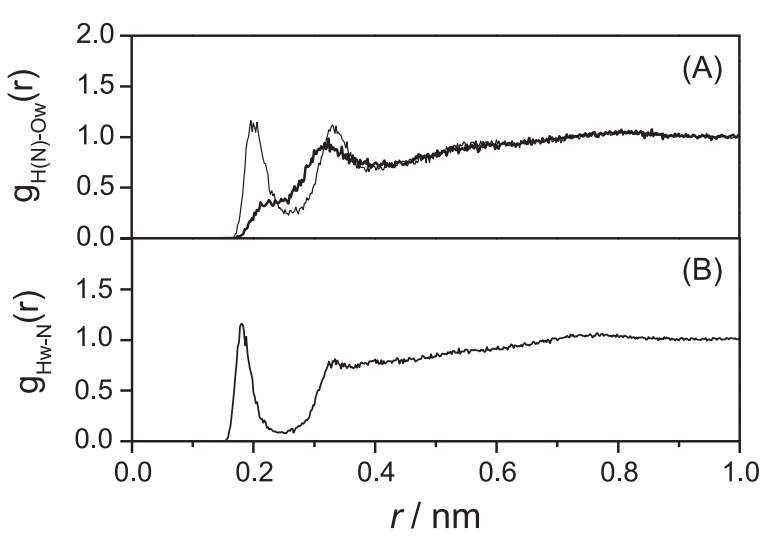

Figure 2. Typical $\mathrm{H}\left(\mathrm{NH}_{2}\right)-\mathrm{O}_{w}$ [(A), bold line], $\mathrm{H}\left(\mathrm{NH}_{3}{ }^{+}\right)-\mathrm{O}_{w}$ [(A), thin line] and $\mathrm{H}_{w}-\mathrm{N}\left(\mathrm{NH}_{2}\right)(\mathrm{B}) \mathrm{RDFs}$, here exemplified for the CHA and $\mathrm{CHA}^{+}$. Similar RDFs were obtained for the other molecules.

More detailed information about the $\mathrm{NH}_{2}$ and $\mathrm{NH}_{3}+$ local hydration structures can be obtained from the $\mathrm{H}\left(\mathrm{NH}_{2}\right)$ $\mathrm{O}_{w}, \mathrm{H}\left(\mathrm{NH}_{3}{ }^{+}\right)-\mathrm{O}_{w}$ and $\mathrm{H}_{w}-\mathrm{N}\left(\mathrm{NH}_{2}\right)$ RDFs (Figure 2) together with the amine-water $\mathrm{H}$-bonds distribution analysis. Looking at the $\mathrm{H}\left(\mathrm{NH}_{2}\right)-\mathrm{O}_{w} \mathrm{RDFs}$, one can see that there is a very weak maximum at $r_{M}=0.22 \mathrm{~nm}\left(N_{w} \approx 0.4\right)$, followed by a much more intense and broader peak at 0.32 or $0.37 \mathrm{~nm}$. Regarding the $\mathrm{H}_{w}-\mathrm{N}\left(\mathrm{NH}_{2}\right) \mathrm{RDFs}$, a well-resolved peak is found at $r_{M}=0.18 \mathrm{~nm}\left(N_{w} \approx 1\right)$. These results suggest that, on average, one water molecule is tightly connected to $\mathrm{NH}_{2}$ as an H-bond donor and 0.8 water molecules are weakly H-bonded to the same group as proton acceptors. The analysis of the H-bond distribution along the trajectory gives identical values for the mean number of $\mathrm{O}_{w}-\mathrm{H} \cdots \mathrm{N}$ and $\mathrm{N}-\mathrm{H} \cdots \mathrm{O}_{w} \mathrm{H}$-bonds, $\sim 1$ and $\sim 0.9$ ( 0.45 for each $\mathrm{H}$-bond $)$, respectively. Two maxima at $r_{M}=0.19$ and $0.33 \mathrm{~nm}$, separated by a deep minimum at $0.26 \mathrm{~nm}$, are observed for the $\mathrm{H}\left(\mathrm{NH}_{3}{ }^{+}\right)-\mathrm{O}_{w}$ RDFs. The first is the preferred site for the $\mathrm{O}_{w}$ atoms, which are $\mathrm{H}$-bonded to the chosen central hydrogen atom and the second corresponds to the more apart $\mathrm{O}_{w}$ atoms, most likely those $\mathrm{H}$-bonded to the two neighbouring hydrogen atoms. The mean value of $N_{w}$ was calculated to be $\sim 1$, meaning that each hydrogen atom of the $\mathrm{NH}_{3}{ }^{+}$group is involved in $\mathrm{N} \mathrm{N}^{+}-\mathrm{H} \cdots \mathrm{O}_{w} \mathrm{H}$-bond. This is also confirmed by the H-bond analysis.

The residence times $(\tau)$ of the water molecules $\mathrm{H}$ bonded to the $\mathrm{NH}_{3}{ }^{+}$and $\mathrm{NH}_{2}$ give a complementary view of the hydration structure. For better comparison purposes, the values of $\tau$ obtained for the different molecules are graphically represented in Figure 3. In $\mathrm{CHA}^{+}$, the mean residence time of the water molecules $\mathrm{H}$-bonded to $\mathrm{NH}_{3}{ }^{+}$ is $\tau=2.3 \mathrm{ps}$, a value close to that reported for protonated methylammonium (2.7 ps) [15]. Concerning CHA, the water molecules $\mathrm{H}$-bonded to $\mathrm{NH}_{2}$ as proton donors have a larger residence time ( $\tau=7.5 \mathrm{ps})$ than those acting as proton acceptors $(\tau=2.2 \mathrm{ps})$. This accounts for the different 


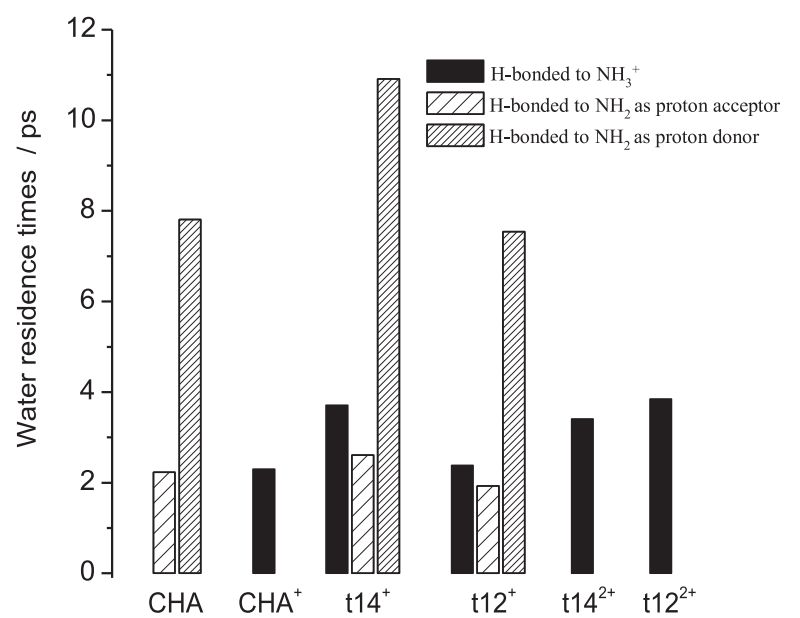

Figure 3. Residence times of the water molecules H-bonded to the $\mathrm{NH}_{2}$ and $\mathrm{NH}_{3}{ }^{+}$groups in the monoamines and protonated diamines.

hydration numbers calculated for the hydrogen and nitrogen atoms of the $\mathrm{NH}_{2}$ group.

When the $\mathrm{NH}_{2}$ and $\mathrm{NH}_{3}{ }^{+}$groups are part of the same molecule, as it happens in the $\mathrm{CHDA}^{+}$isomers, the residence times vary considerably relative to the monoamines. In $114^{+}$, the value of $\tau$ increases by $17 \%$ for the water molecules $\mathrm{H}$-acceptors from $\mathrm{NH}_{2}, 40 \%$ for those $\mathrm{H}$-bonded to the nitrogen lone-pair and $61 \%$ for those connected to $\mathrm{NH}_{3}{ }^{+}$. It should be noted that these data provide a much clearer picture about the effect of the mutual influence of the groups on hydration than those derived from the RDFs. When the amino groups are in vicinal position, practically all the residence times decrease due to the $\mathrm{N}^{+}-\mathrm{H} \cdots \mathrm{N}$ intramolecular H-bond. In the diprotonated diamines, the interference between the charged groups increases the water residence time by 1.5 times in $\mathrm{t} 14^{2+}$ and by 1.7 times in $\mathrm{t}^{2} 2^{2+}$, relative to $\mathrm{CHA}^{+}$.

\subsection{Amine-water complexes}

\subsubsection{Optimised geometries}

Geometrically, an H-bond is commonly characterised by the distance between the hydrogen and the acceptor atom $(d)$, as well as by the angle defined by the donor-hydrogenacceptor atoms $(\alpha)$. It is stronger when the distance is shorter and the angle is closer to $180^{\circ}$. For hydrogen bonds involving $\mathrm{OH}$ and $\mathrm{NH}$ groups, distances smaller than 2.7 $\AA$, a value corresponding to the sum of the van der Waals radii [36] and angles above $110^{\circ}$ are generally accepted as the criteria for the presence of an $\mathrm{H}$-bond $[38,40]$.

The B3LYP/aug-cc-pVDZ-optimised geometries of the $\mathrm{CHA} \cdot 3 \mathrm{H}_{2} \mathrm{O}, \mathrm{CHA}^{+} \cdot 3 \mathrm{H}_{2} \mathrm{O}, \mathrm{CHDA}^{+} \cdot 6 \mathrm{H}_{2} \mathrm{O}$ and CHDA $^{2+} .6 \mathrm{H}_{2} \mathrm{O}$ complexes are presented in Figures 4-6. The distances and angles characterising the $\mathrm{H}$-bonds in the various complexes are included in the figures.

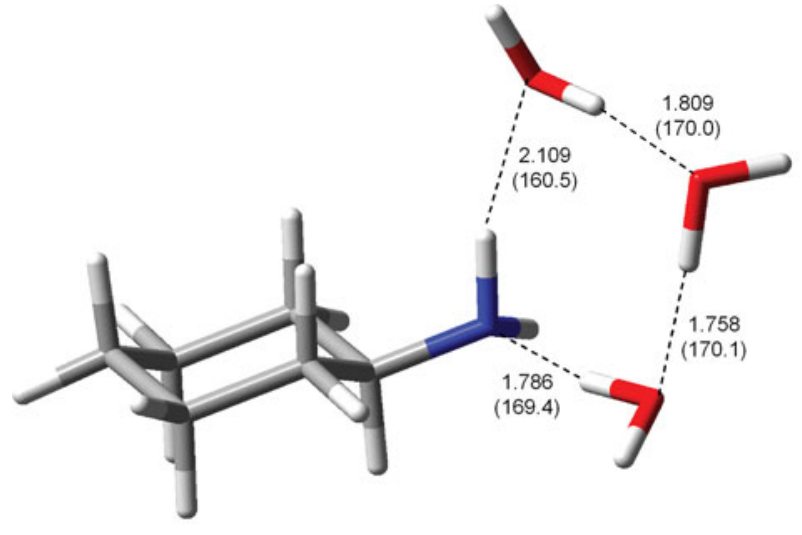

CHA. $3 \mathrm{H}_{2} \mathrm{O}$

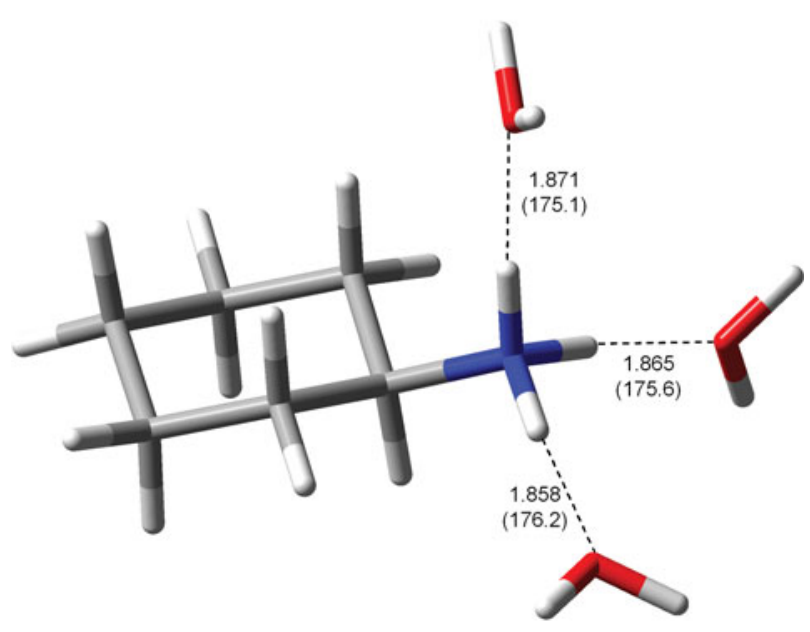

$\mathrm{CHA}^{+} .3 \mathrm{H}_{2} \mathrm{O}$

Figure 4. Optimised geometries (B3LYP/aug-cc-pVDZ) of the CHA. $3 \mathrm{H}_{2} \mathrm{O}$ and $\mathrm{CHA}^{+} \cdot 3 \mathrm{H}_{2} \mathrm{O}$ complexes showing the $\mathrm{H}$-bond distances and angles. H-bonds are represented by dotted lines.

The arrangement of the water molecules around the $\mathrm{NH}_{2}$ group is illustrated in the $\mathrm{CHA} \cdot 3 \mathrm{H}_{2} \mathrm{O}$ hydrate (Figure 4). Two water molecules are $\mathrm{H}$-bonded to the $\mathrm{NH}_{2}$ group, one acting as a proton donor and the other as a proton acceptor. According to the H-bond parameters, the $\mathrm{O}_{w}-\mathrm{H} \cdots \mathrm{N}$ H-bond $\left(d=1.79 \AA, \alpha=169^{\circ}\right)$ is much stronger than the $\mathrm{N}-\mathrm{H} \cdots \mathrm{O}_{w}$ one $\left(d=2.11 \AA, \alpha=160^{\circ}\right)$. The third water molecule is connected to the other two giving rise to a cyclic H-bonded complex. The structure exhibited by the $\mathrm{CHA}^{+} \cdot 3 \mathrm{H}_{2} \mathrm{O}$ complex is that expected from the strong donor character of the $\mathrm{NH}_{3}{ }^{+}$group. Each water molecule is firmly bonded to the charged group through an $\mathrm{N}^{+}-\mathrm{H} \cdots \mathrm{O}_{w}$ charge-assisted H-bond $\left(d=1.86 \AA, \alpha=176^{\circ}\right)$ and, consequently, no $\mathrm{H}$-bonds are established between the water molecules. This type of structure is in agreement with that found for ammonium and methylammonium-water clusters $[21,41]$. 
It is now interesting to compare the structures of the CHA $3 \mathrm{H}_{2} \mathrm{O}$ and $\mathrm{CHA}^{+} \cdot 3 \mathrm{H}_{2} \mathrm{O}$ complexes with the data provided from the MD simulations, particularly in what the amine-water $\mathrm{H}$-bonds is concerned. Firstly, the number of $\mathrm{NH}_{2}$-water and $\mathrm{NH}_{3}{ }^{+}$-water $\mathrm{H}$-bonds in the optimised complexes corresponds to that found in aqueous solutions, as revealed by the RDFs and H-bond distribution analysis. Secondly, the H-bond distances in the above complexes are very close to the values of the first maximum distances $\left(r_{M}\right)$ taken from the $\mathrm{N}\left(\mathrm{NH}_{2}\right)-\mathrm{H}_{w}(1.8 \AA), \mathrm{H}\left(\mathrm{NH}_{2}\right)-\mathrm{O}_{w}(2.2 \AA)$ and $\mathrm{H}\left(\mathrm{NH}_{3}{ }^{+}\right)-\mathrm{O}_{w}(1.9 \AA) \mathrm{RDFs}$. Therefore, it can be concluded that the main structural features of the first hydration shell around the $\mathrm{NH}_{2}$ and $\mathrm{NH}_{3}{ }^{+}$groups are well described by the gas-phase complexes.

The optimised $\mathrm{CHDA}^{+} \cdot 6 \mathrm{H}_{2} \mathrm{O}$ complexes shown in Figure 5 exhibit significant differences relative to the complexes of the isolated monoamines. In $\mathrm{t} 14^{+} \cdot 6 \mathrm{H}_{2} \mathrm{O}$, a bridge consisting of three water molecules between both amino groups is set up. Each water molecule acts both as a proton donor and as a proton acceptor, an arrangement stabilised by H-bond cooperativity [42-45]. Owing to the relative po- sitioning of the amino groups in the $\mathrm{c} 13^{+} .6 \mathrm{H}_{2} \mathrm{O}$ complex, two water bridges are formed between the amino groups. The water molecule that is H-bonded to the nitrogen lonepair acts as a double acceptor of the two nearest water molecules, giving rise to an anticooperative effect [38]. The coexistence of both effects is responsible for the diversity of H-bond strengths among the water molecules.

The optimised hexahydrate of the $12^{+}$isomer, built according to the methodology described above, is represented in Figure 5 as $112^{+} \cdot 6 \mathrm{H}_{2} \mathrm{O}-(\mathrm{A})$. Two water bridges connect the amino groups with one water molecule acting as a double acceptor, as in the $\mathrm{c} 13^{+} \cdot 6 \mathrm{H}_{2} \mathrm{O}$ complex, and another as a double donor. A relevant feature of this complex is the absence of an $\mathrm{N}^{+}-\mathrm{H} \cdots \mathrm{N}$ intramolecular $\mathrm{H}$-bond as confirmed by the values of the $\mathrm{H}\left(\mathrm{NH}_{3}{ }^{+}\right) \cdots \mathrm{N}$ distance $(2.78 \AA$ ) and the $\mathrm{N}^{+}-\mathrm{H} \cdots \mathrm{N}$ angle $\left(88.0^{\circ}\right)$. Nevertheless, this is not consistent with the results of the MD simulation, nor with the data on the implicit hydration of charged diamines [22]. To answer the doubt about the preferred conformation of $\mathrm{t} 12^{+}$in solution, an intramolecularly H-bonded complex was built and its optimised geometry is shown in Figure 5,
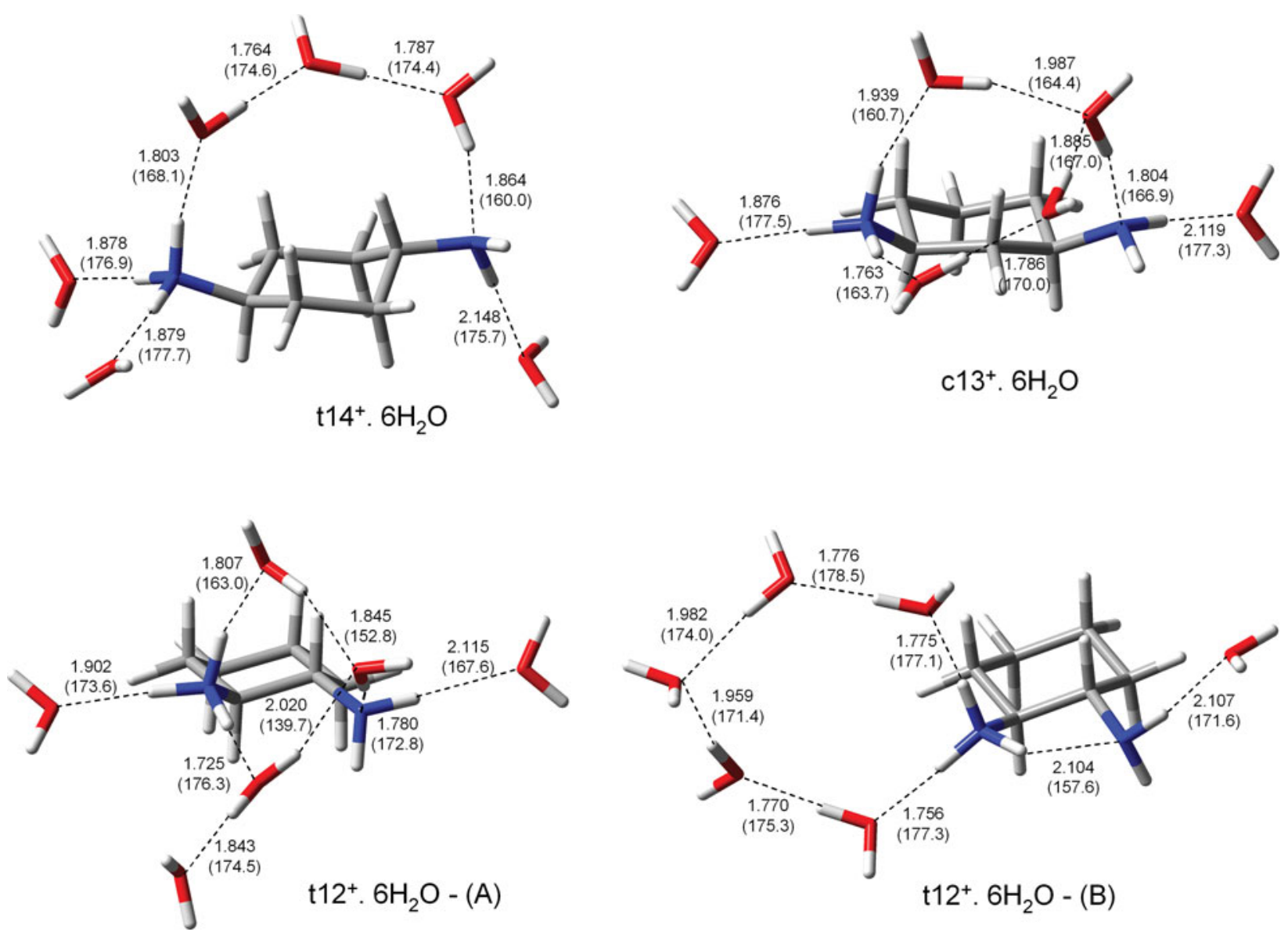

Figure 5. Optimised geometries (B3LYP/aug-cc-pVDZ) of the CHDA ${ }^{+} \cdot 6 \mathrm{H}_{2} \mathrm{O}$ complexes showing the $\mathrm{H}-$ bond distances and angles. $\mathrm{H}$-bonds are represented by dotted lines. 
$\mathrm{t} 12^{+} \cdot 6 \mathrm{H}_{2} \mathrm{O}-(\mathrm{B})$. Here, five water molecules form a cyclic structure around the $\mathrm{NH}_{3}{ }^{+}$group, allowing the establishment of an $\mathrm{N}^{+}-\mathrm{H} \cdots \mathrm{N}$ intramolecular $\mathrm{H}$-bond. Its existence is confirmed by the $\mathrm{H}\left(\mathrm{NH}_{3}{ }^{+}\right) \cdots \mathrm{N}$ distance $(2.10 \AA)$ and the $\mathrm{N}^{+}-\mathrm{H} \cdots \mathrm{N}$ angle $\left(116.9^{\circ}\right)$. Since the calculated Gibbs energy of complex (B) was found to be $7 \mathrm{~kJ} \mathrm{~mol}^{-1}$ lower than that of complex (A), it can be concluded that the former structure prevails in aqueous solution and is therefore the one that will be considered in the following discussion.

A common feature of the $\mathrm{CHDA}^{+} \cdot 6 \mathrm{H}_{2} \mathrm{O}$ complexes is that the cooperativity/anticooperativity of the water $\mathrm{H}$ bonds is extended to the H-bonds involving the amino groups and the bridged water molecules, resulting in variations of their strength (see Figure 5). This effect provides a plausible molecular explanation for the structural modifications occurring in the $\mathrm{NH}_{2}$ and $\mathrm{NH}_{3}{ }^{+}$hydration shells, when the groups are placed together, as revealed by the MD simulations.

The optimised structures of the $\mathrm{CHDA}^{2+} .6 \mathrm{H}_{2} \mathrm{O}$ hydrates are displayed in Figure 6. Unlike the monoprotonated forms, in the $114^{2+} .6 \mathrm{H}_{2} \mathrm{O}$ and $\mathrm{c} 13^{2+} .6 \mathrm{H}_{2} \mathrm{O}$ complexes, the water molecules are strongly held by the charged groups, thereby originating two independent hydration spheres. Interaction between water molecules is only observed in the $112^{2+} \cdot 6 \mathrm{H}_{2} \mathrm{O}$ complex. The values of the geometrical parameters included in Figure 6 show that, in general, stronger $\mathrm{NH}_{3}{ }^{+}$-water $\mathrm{H}$-bonds are formed in between as the groups approximate each other. Such H-bond strengthening, mainly caused by the charge repulsion, certainly contributes to the larger residence times of the water molecules around the $\mathrm{NH}_{3}{ }^{+}$groups in the $\mathrm{CHDA}^{2+}$ isomers than in $\mathrm{CHA}^{+}$.

\subsubsection{Thermodynamics of complexation}

The thermodynamic properties corresponding to the formation of the amine-water complexes, calculated through Equation (2), are given in Table 2. As far as we know, no experimental data on gas-phase hydration have been published for protonated cyclohexylamine or CHDAs, but only for protonated alkylamines and alkyldiamines [17,19]. Although no direct comparison can be made, one can state that the experimental enthalpies and Gibbs energies published for those amines are consistent with the values reported here.

As a consequence of the intermolecular H-bonds of the amino groups with water, negative values of $\Delta E_{\text {complex }}$ and $\Delta H_{\text {complex }}$ have been estimated for the amine-water complex formation. This process is also accompanied by a pronounced entropy decrease. Since the values of $\Delta S_{\text {complex }}$ calculated for hexahydrates are roughly twice as those calculated for the trihydrates, we come to the conclusion that $\Delta S_{\text {complex }}$ is dominated by the entropy loss of the water molecules.
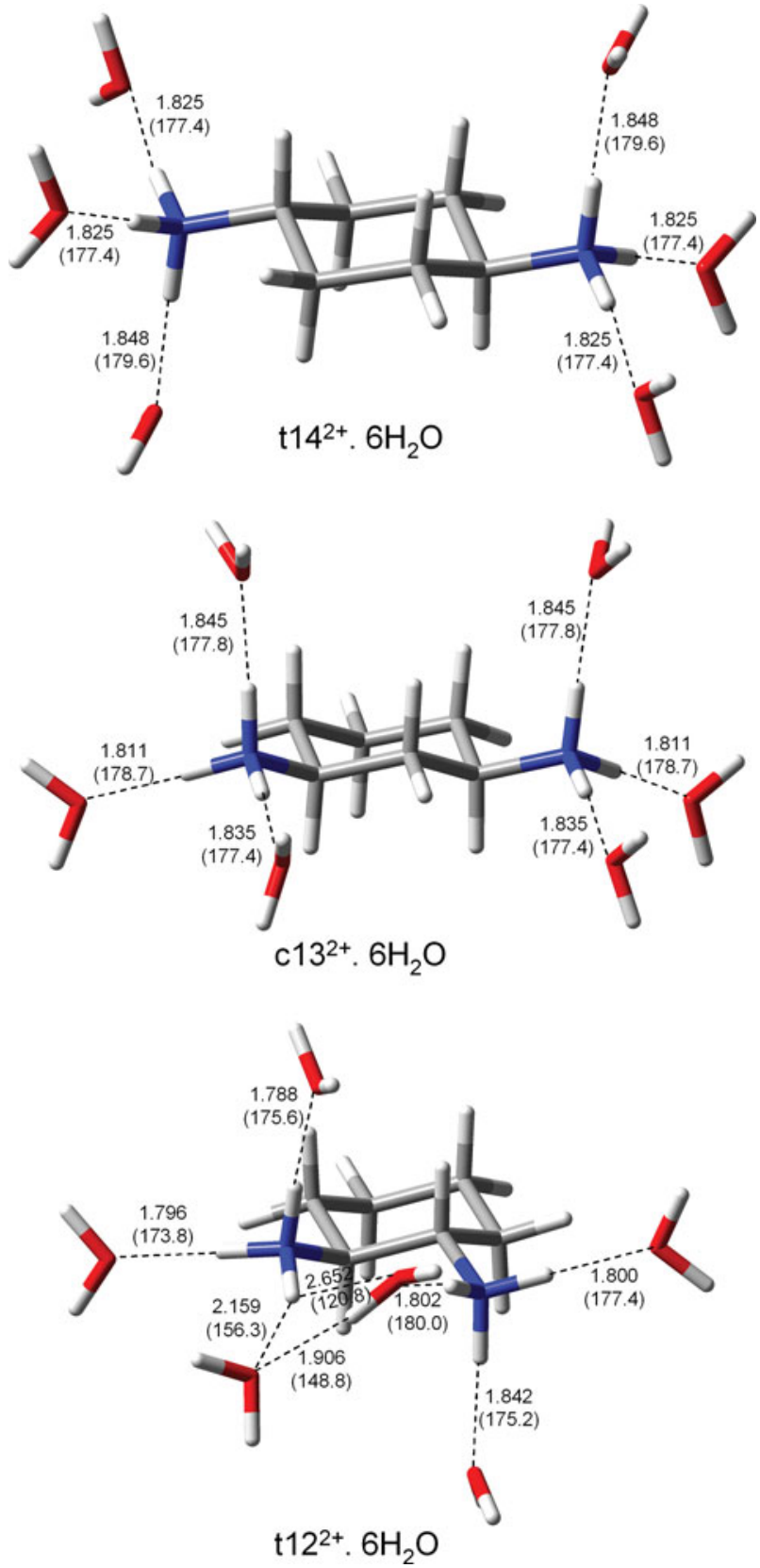

Figure 6. Optimised geometries (B3LYP/aug-cc-pVDZ) of the $\mathrm{CHDA}^{2+} \cdot 6 \mathrm{H}_{2} \mathrm{O}$ complexes showing the H-bond distances and angles. H-bonds are represented by dotted lines.

Owing to the entropy compensation, the absolute values of $\Delta G_{\text {complex }}$ are much lower than those of $\Delta E_{\text {complex }}$ or $\Delta H_{\text {complex }}$, which renders the first quantity less sensitive to describe the systems under study in energetic terms. Therefore, we use $\Delta H_{\text {complex }}$ in the discussion that follows. Comparing CHA $3 \mathrm{H}_{2} \mathrm{O}$ with $\mathrm{CHA}^{+} \cdot 3 \mathrm{H}_{2} \mathrm{O}$, one can see that the amino group protonation lowers the enthalpy of complex formation by $-65 \mathrm{~kJ} \mathrm{~mol}^{-1}$. This is in agreement with the strengthening of the $\mathrm{N}-\mathrm{H} \cdots \mathrm{O}_{w} \mathrm{H}$-bonds caused by the presence of the charge. In $114^{+} .6 \mathrm{H}_{2} \mathrm{O}$ and 
Table 2. Thermodynamic functions corresponding to the formation of amine-water complexes calculated at the B3LYP/augcc-pVDZ level of theory. ${ }^{a}$

\begin{tabular}{lcccc}
\hline Hydrate & $\Delta E_{\text {complex }} / \mathrm{kJ} \mathrm{mol}^{-1}$ & $\Delta H_{\text {complex }} / \mathrm{kJ} \mathrm{mol}^{-1}$ & $\Delta G_{\text {complex }} / \mathrm{kJ} \mathrm{mol}^{-1}$ & $\Delta S_{\text {complex }} / \mathrm{J} \mathrm{K}^{-1} \mathrm{~mol}^{-1}$ \\
\hline $\mathrm{CHA} \cdot 3 \mathrm{H}_{2} \mathrm{O}$ & -99.65 & -77.95 & 31.36 & -366.64 \\
$\mathrm{CHA}+3 \mathrm{H}_{2} \mathrm{O}$ & -161.05 & -142.94 & -54.70 & -295.96 \\
$\mathrm{t} 14^{+} \cdot 6 \mathrm{H}_{2} \mathrm{O}$ & -278.53 & -237.85 & -36.21 & -676.30 \\
$\mathrm{c} 13^{+} .6 \mathrm{H}_{2} \mathrm{O}$ & -293.53 & -251.42 & -31.64 & -737.15 \\
$\mathrm{t} 12^{+} \cdot 6 \mathrm{H}_{2} \mathrm{O}$ & -250.00 & -217.80 & -18.89 & -667.15 \\
$\mathrm{t} 14^{2+} \cdot 6 \mathrm{H}_{2} \mathrm{O}$ & -424.60 & -388.44 & -202.58 & -623.38 \\
$\mathrm{c}^{2} 3^{2+} \cdot 6 \mathrm{H}_{2} \mathrm{O}$ & -431.63 & -394.99 & -203.91 & -640.89 \\
$\mathrm{t}^{2+} .6 \mathrm{H}_{2} \mathrm{O}$ & -473.43 & -434.48 & -232.62 & -677.04 \\
\hline
\end{tabular}

${ }^{a}$ Calculated entropy of a water molecule: $S_{w}$, trans $=144.80 \mathrm{~J} \mathrm{~K}^{-1} \mathrm{~mol}^{-1}, S_{w, \text { rot }}=43.90 \mathrm{~J} \mathrm{~K}^{-1} \mathrm{~mol}^{-1}, S_{w, \mathrm{vib}}=0.029 \mathrm{~J} \mathrm{~K}^{-1} \mathrm{~mol}^{-1}$.

$\mathrm{c} 13^{+} \cdot 6 \mathrm{H}_{2} \mathrm{O}, \Delta H_{\text {complex }}$ is more negative by $17-31 \mathrm{~kJ} \mathrm{~mol}^{-1}$ than the sum of the values obtained for the two monoamines. This difference increases as the groups approximate each other, except for the $112^{+} .6 \mathrm{H}_{2} \mathrm{O}$ because of the reasons mentioned above. From this result, one can conclude that the mutual interference between the amino groups in the monoprotonated diamines leads to an overall strengthening of the water-amine interactions. This is in agreement with the information drawn from the MD simulations.

The interference between the amino groups is much more pronounced in the diprotonated forms. In fact, the values of $\Delta H_{\text {complex }}$ calculated for the hexahydrates are 103-149 $\mathrm{kJ} \mathrm{mol}^{-1}$ more negative than twice the values found for $\mathrm{CHA}^{+} \cdot 3 \mathrm{H}_{2} \mathrm{O}$. Also, within the different isomers, $\Delta H_{\text {complex }}$ becomes more negative as the groups approximate each other. This result is a direct consequence of the $\mathrm{NH}_{3}{ }^{+}$-water $\mathrm{H}$-bonds strengthening as the charges become closer together.

\section{Final remarks}

New and relevant data on the hydration of monoamines (neutral and charged forms) and protonated diamines have been presented in this work, which can be used to better understand the structure of polyamines in aqueous solution. Two points deserved particular attention: the structural organisation of the water molecules around the neutral and charged amino groups and the effect of the presence of more than one amino group in the same molecule on the hydration structure.

The results of the MD simulations lead to the conclusion that in a CHA aqueous solution, a strong and persistent $\mathrm{NH}_{2}$-water $\mathrm{H}$-bond is established with the nitrogen lone-pair, while weaker and more intermittent ones are formed through the $\mathrm{N}-\mathrm{H}$ bonds. On average, two water molecules describe the primary hydration shell of the $\mathrm{NH}_{2}$ group. A similar H-bonding pattern is exhibited by the CHA $3 \mathrm{H}_{2} \mathrm{O}$ complex. Regarding $\mathrm{CHA}^{+}$, both computational approaches indicate the formation of three strong H-bonds between the $\mathrm{NH}_{3}{ }^{+}$group and the surrounding wa- ter molecules. The results of the MD simulations suggest that besides these three water molecules, a fourth one is present in the first hydration shell.

A very important conclusion drawn from this work deals with the effect of the mutual influence of the amino groups on their interactions with water. Geometric and energetic data taken from the optimised $\mathrm{CHDA}^{+} .6 \mathrm{H}_{2} \mathrm{O}$ and $\mathrm{CHDA}^{2+} .6 \mathrm{H}_{2} \mathrm{O}$ complexes clearly reveal that, in general, the amine-water interactions are intensified relative to those expected from the individual contribution of the groups. This behaviour is interpreted in the monoprotonated forms by the formation of cooperatively $\mathrm{H}$-bonded water bridges between the $\mathrm{NH}_{3}{ }^{+}$and $\mathrm{NH}_{2}$ groups and in the diprotonated forms by the electrostatic repulsion between the two charges. The only exception to this general trend occurs in the $112^{+} .6 \mathrm{H}_{2} \mathrm{O}$ complex due to the formation of an intramolecular H-bond. Notably, a similar behaviour is found in aqueous solution from the comparison of the water residence times, hydration numbers and characteristics of the RDF peaks, obtained for monoamines and protonated diamines. It can thus be concluded that the molecular features individualised in gas-phase hydration play an important role in aqueous solution.

\section{References}

[1] S.A. Lawrence, Amines: Synthesis, Properties and Applications (Cambridge University Press, New York, 2004).

[2] S. Patai, The Chemistry of the Amino Group (Interscience Publishers, London, 1968).

[3] A. Ricci, Amino Group Chemistry: From Synthesis to the Life Sciences (Wiley-VCH, Weinheim, 2008).

[4] A.J.L. Jesus, M. Helena, S.F. Teixeira, and J.S. Redinha, J. Phys. Chem. B 116, 5019 (2012).

[5] V.S. Bryantsev, M.S. Diallo, and W.A. Goddard, J. Phys. Chem. A 111, 4422 (2007).

[6] C. Perrin, B. Dempsey, and E.P. Serjeant, $p K a$ Prediction of Organic Acids and Bases (Chapman \& Hall, London, 1981).

[7] C. Moinard, Luc Cynober, and J.-P. de Bandt, Clin. Nutr. 24, 184 (2005)

[8] A. Gugliucci, Clin. Chim. Acta 344, 23 (2004).

[9] K. Igarashi and K. Kashiwagi, Biochem. Biophys. Res. Commun. 271, 559 (2000). 
[10] R.A. Casero and L.J. Marton, Nat. Rev. Drug Discov. 6, 373 (2007).

[11] H.C. Ha, N.S. Sirisoma, P. Kuppusamy, J.L. Zweier, P.M. Woster, and R.A. Casero, Proc. Natl. Acad. Sci. 95, 11140 (1998).

[12] F. Brugé, M. Bernasconi, and M. Parrinello, J. Am. Chem. Soc. 121, 10883 (1999).

[13] P. Intharathep, A. Tongraar, and K. Sagarik, J. Comput. Chem. 26, 1329 (2005).

[14] D. Liu, T. Wyttenbach, and M.T. Bowers, Int. J. Mass Spectrom. 236, 81 (2004).

[15] H. Hesske and K. Gloe, J. Phys. Chem. A 111, 9848 (2007).

[16] E.C. Meng, J.W. Caldwell, and P.A. Kollman, J. Phys. Chem. 100, 2367 (1996).

[17] M. Mautner, J. Am. Chem. Soc. 106, 1265 (1984).

[18] P. George, J.P. Glusker, G.D. Markham, M. Trachtman, and C.W. Bock, Mol. Phys. 101, 2451 (2003).

[19] A.T. Blades, J.S. Klassen, and P. Kebarle, J. Am. Chem. Soc. 118, 12437 (1996).

[20] J.J. Dannenberg and L.K. Vinson, J. Phys. Chem. 92, 5635 (1988).

[21] D.W. Boo, Bull. Korean Chem. Soc. 22, 693 (2001).

[22] A.J. Lopes Jesus and J.S. Redinha, J. Phys. Chem. A 115, 14069 (2011)

[23] L.D. Schuler, X. Daura, and W.F. van Gunsteren, J. Comput. Chem. 22, 1205 (2001).

[24] A.W. Schuttelkopf and D.M.F. van Aalten, Acta Crystallogr. D 60, 1355 (2004).

[25] C.M. Breneman and K.B. Wiberg, J. Comput. Chem. 11, 361 (1990).

[26] B. Hess, C. Kutzner, D. van der Spoel, and E. Lindahl, J. Chem. Theory Comput. 4, 435 (2008).

[27] R.M. Lynden-Bell and S.H. Lee, J. Phys. Chem. B 102, 4193 (1998).

[28] A.D. Becke, Phys. Rev. A 38, 3098 (1988).

[29] A.D. Becke, J. Chem. Phys. 98, 5648 (1993).

[30] C.T. Lee, W.T. Yang, and R.G. Parr, Phys. Rev. B 37, 785 (1988).

[31] T.H. Dunning, Jr., J. Chem. Phys. 90, 1007 (1989).

[32] D.E. Woon and T.H. Dunning, Jr., J. Chem. Phys. 98, 1358 (1993).
[33] S.F. Boys and F. Bernardi, Mol. Phys. 19, 553 (1970).

[34] S. Sílvia, D. Miquel, and J.J. Dannenberg, J. Chem. Phys. 105, 11024 (1996)

[35] M.J. Frisch, G.W. Trucks, H. B. Schlegel, G.E. Scuseria, M.A. Robb, J.R. Cheeseman, J.A. Montgomery Jr., T. Vreven, K.N. Kudin, J.C. Burant, J.M. Millam, S.S. Iyengar, J. Tomasi, V. Barone, B. Mennucci, M. Cossi, G. Scalmani, N. Rega, G.A. Petersson, H. Nakatsuji, M. Hada, M. Ehara, K. Toyota, R. Fukuda, J. Hasegawa, M. Ishida, T. Nakajima, Y. Honda, O. Kitao, H. Nakai, M. Klene, X. Li, J.E. Knox, H.P. Hratchian, J.B. Cross, V. Bakken, C. Adamo, J. Jaramillo, R. Gomperts, R.E. Stratmann, O. Yazyev, A.J. Austin, R. Cammi, C. Pomelli, J.W. Ochterski, P.Y. Ayala, K. Morokuma, G.A. Voth, P. Salvador, J.J. Dannenberg, V.G. Zakrzewski, S. Dapprich, A.D. Daniels, M.C. Strain, O. Farkas, D.K. Malick, A.D. Rabuck, K. Raghavachari, J.B. Foresman, J.V. Ortiz, Q. Cui, A.G. Baboul, S. Clifford, J. Cioslowski, B.B. Stefanov, G. Liu, A. Liashenko, P. Piskorz, I. Komaromi, R.L. Martin, D.J. Fox, T. Keith, M.A. Al-Laham, C.Y. Peng, A. Nanayakkara, M. Challacombe, P.M.W. Gill, B. Johnson, W. Chen, M.W. Wong, C. Gonzalez, and J.A. Pople, Gaussian 03, Revision D.01 (Gaussian, Inc., Wallingford, CT, 2004).

[36] A. Bondi, J. Phys. Chem. 68, 441 (1964).

[37] G.K. Peter, B. Dan, and L. Aatto, J. Chem. Phys. 113, 8036 (2000).

[38] T. Steiner, Angew. Chem. -Int. Edit. 41, 48 (2002).

[39] S.J. Grabowski, Hydrogen Bonding - New Insights (Springer, Dordrecht, 2006).

[40] G.A. Jeffrey, An Introduction to Hydrogen Bonding (Oxford University Press, Oxford, 1997)

[41] Y.-S. Wang, H.-C. Chang, J.-C. Jiang, S.H. Lin, Y.T. Lee, and H-C. Chang, J. Am. Chem. Soc. 120, 8777 (1998).

[42] H.S. Frank and W.-Y Wen, Discuss. Faraday Soc. 24, 133 (1957).

[43] F. Weinhold, J. Chem. Phys. 109, 373 (1998).

[44] R. Ludwig, Phys. Chem. Chem. Phys. 4, 5481 (2002).

[45] P. Barnes, J.L. Finney, J.D. Nicholas, and J.E. Quinn, Nature 282, 459 (1979). 